\title{
COMUNICAÇÃO DE CONFLITOS: ENUNCIADOS DE CAATINGUEIROS ATRAVESSADOS POR OUTROS MUNDOS ${ }^{1}$
}

Aurilene Rodrigues ${ }^{2}$

\section{RESUMO}

Este artigo analisa o modo pelo qual os processos comunicacionais dos caatingueiros nos fazem ver os sentidos produzidos acerca dos conflitos vivenciados por eles com a chegada de projetos modernizantes na caatinga. O objetivo principal foi tornar sensíveis as suas expressões linguageiras, historicamente ignoradas A interpretação deu-se por meio da Análise do Discurso. Dentre todos os conflitos, o maior de todos é o desaparecimento do povo caatingueiro e com ele um modo de existência.

Palavras-chave: processos comunicacionais; discurso; caatingueiros; Caatinga; modernização.

\section{COMMUNICATION OF CONFLICTS: STATEMENTS FROM CAATINGUEIROS ACROSS FOR OTHER WORLDS}

\begin{abstract}
This article analyzes the way in which the communicational processes of the caatingueiros make us see the senses produced about the conflicts they experience with the arrival of modernizing projects in the caatinga. The main objective was to make sensitive their language expressions, historically ignored. The interpretation took place through Discourse Analysis. Among all the conflicts, the biggest one is the disappearance of the Caatingueiro people and with it a way of existence.
\end{abstract}

Keywords: communicational processes; speech; caatingueiros; Caatinga; modernization.

\section{COMUNICACIÓN DE CONFLICTOS: DECLARACIONES DE CAATINGUEIROS A TRAVÉS PARA OTROS MUNDOS}

\section{RESUMEN}

Este artículo analiza la forma en que los procesos comunicacionales de los caatingueiros nos hacen ver los sentidos producidos sobre los conflictos vividos por ellos con la llegada de proyectos modernizadores a la caatinga. El objetivo principal fue sensibilizar sus expresiones lingüísticas, históricamente ignoradas, la interpretación se realizó a través del Análisis del

\footnotetext{
1 Trabalho apresentado no Conexão Pós:Resistência pela Ciência e Colaboração na Pesquisa do Programa de Pós-Graduação em Ciências da Comunicação da Escola de Comunicações e Artes da Universidade de São Paulo. São Paulo, 5 e 6 de dezembro de 2019.

2 Doutora em Comunicação (UNEB/USP). Docente no DCH-III (UNEB). Juazeiro-BA. Brasil. Email:arlima@uneb.br
} 
Discurso. Entre todos los conflictos, el mayor es la desaparición del pueblo caatingueiro y con ello una forma de existencia.

Palabras clave: procesos comunicacionales; discurso; caatingueiros; Caatinga; modernización.

\section{Introdução}

Este artigo faz um recorte da tese de doutorado ${ }^{3}$ defendida em junho de 2020 acerca da comunicação de conflitos enunciados por caatingueiros do Sertão do São Francisco. Esses enunciados e os processos de enunciação materializados nesse trabalho nos fazem ver que os projetos modernizantes ${ }^{4}$ que atravessam o mundo caatingueiro ${ }^{5}$ não se sustentam se forem considerados a partir das problematizações dos próprios caatingueiros. Os processos comunicacionais analisados demonstram que os conflitos são enunciados desde o ponto de vista do modo de existência dessa população e o maior deles parece ser o fato de que para os projetos vingarem tal como foram concebidos, o povo precisa desaparecer. Não se trata de um objetivo explicitado pelos projetos, mas a forma como esses vêm sendo implantados, excluir a população local parece ser uma condição. Para os caatingueiros é o aprofundamento dos problemas.

A pesquisa demonstrou que as expressões linguageiras dos caatingueiros não são ouvidas e nem foram previstas nesses projetos. As falas transcritas das entrevistas com os caatingueiros, assim como os documentos analisados demonstram que os discursos dos representantes desses projetos ignoram ou acreditam que se opõem à perspectiva caatingueira dentro de noções vagas, como por exemplo a noção de desenvolvimento. Procurei demostrar que os sentidos produzidos por essa população acerca desses conflitos são passíveis de serem ouvidos e compreendidos, mas isso exige uma atenção diferente. É preciso ouvi-los como uma manifestação própria, fora dos discursos dominantes. Os processos comunicacionais dos caatingueiros são praticados como ato

\footnotetext{
3 "Comunicação de conflitos - enunciados de caatingueiros atravessados por outros mundos" - ECA/USP $-2020$

${ }^{4}$ Criação de um Parque de Conservação, o Boqueirão da Onça; Instalação de Parques Eólicos e Exploração de Minérios por grandes empresas mineradoras.

${ }^{5}$ Lugar onde hoje se denomina bioma caatinga e onde habita uma população que se auto-denomina de caatingueiros. Neste trabalho me refiro à população caatingueira do município de Sento-Sé Bahia.
} 
político, mesmo sem forças suficientes para intervir, desenvolvendo a enunciação de novos problemas diante dos acontecimentos.

Para dar materialidade discursiva a essas questões busquei na tese, mapear a comunicação que ora se efetiva "nas caatinga", atravessando esse mundo; interpretar a comunicação dos caatingueiros, ouvindo a língua "das caatinga"; caracterizar essa população e seus modos de existência; comunicar os conflitos enunciados por eles, apontando os problemas formulados; discutir as questões epistemológicas e políticas implicadas nos processos comunicacionais que envolvem modos de vida tradicional e projetos de modernização.

Para o desenvolvimento da tese me vali dos procedimentos metodológicos da pesquisa empírica, adotando apenas traços de alguns procedimentos da pesquisa etnográfica (GEERTZ, 2008) uma vez que esse tipo de pesquisa implicaria em um trabalho exaustivo, considerando a dimensão do município ${ }^{6}$ e a abrangência do campo problemático. $\mathrm{O}$ apelo a um método que tem a sua origem na antropologia se dá não por haver uma divergência de opinião entre os objetivos dos projetos e os dos caatingueiros, mas uma diferença cultural, pois não se trata de ouvir uma outra parte de uma realidade, mas ouvir de outro modo.

Travancas (2011, p.100) ressalta que "a etnografia faz parte do trabalho de campo do pesquisador. E é entendida como um método de pesquisa qualitativa e empírica que apresenta características específicas”. Considerar essa pesquisa como um campo empírico, foi o grande desafio.

Tentei ser fiel à linguagem dessa gente no uso das suas palavras e no modo como as dizem, uma língua em movimento, fortemente marcada por traços da oralidade e ancorada nos saberes da experiência e do pertencimento ao seu território existencial. Ao ouvir, transcrever, traduzir e contextualizar atentamente as falas desse povo pude perceber a intensidade e a complexidade dos conflitos que emergem nos seus enunciados e nos seus processos de enunciação. Esses processos foram referenciados no arcabouço teórico da Análise de Discurso Francesa (ADF), sobretudo nas obras de Bakhtin/Voloshinov (2006) e Authier-Revus (2004) e nos estudos de pesquisadores

\footnotetext{
${ }^{6}$ De acordo com dados do IBGE - Instituto Brasileiro de Geografia e Estatística (2010), o município está situado em uma área de $12871,039 \mathrm{~km}^{2}$, sendo a terceira maior extensão territorial do Estado da Bahia, com uma população estimada de 40.703 hab.
} 
brasileiros a exemplo de Roseli Fígaro (2012) e Helena Nagamini Brandão (2012). Esses e outros autores contribuíram na condução das análises, embora nem sempre tenham sido citados diretamente.

\section{Comunicação de caatingueiros: ouvindo a língua das caatingas}

Dominique Wolton (2004, p. 15), no livro "Pensar a Comunicação", diz que "o mais fácil, na comunicação, ainda são as ferramentas; o mais complicado, os homens e a sociedade". Esse trabalho trata justamente desse segundo aspecto: as relações de comunicação entre o povo caatingueiro e agentes da modernização. Nesse sentido, esse autor compreende que

A comunicação é, antes de mais nada, uma experiência antropológica fundamental. Do ponto de vista intuitivo, comunicar consiste em compartilhar com o outro. Simplesmente não há vida individual e coletiva sem comunicação. E o que caracteriza cada experiência pessoal, como a de qualquer sociedade, é definir regras de comunicação. Não há seres humanos sem sociedade, como não há sociedade sem comunicação. E é por isso que a comunicação é, ao mesmo tempo, uma realidade e um modelo cultural. (Wolton, 2004, p.30)

A dimensão antropológica da comunicação é um aspecto fundamental desse trabalho, uma vez que se propõe a discutir o modo de pensar e de se comunicar de um grupo social, tradicional, frente a projetos modernizantes que atravessam o seu mundo.

Compreendo a comunicação da mesma forma explicitada por Fígaro (2012, p.10): como sendo uma "característica constitutiva do humano, presente em toda relação social". Essa concepção contraria a ideia de comunicação como mera informação. Um outro aspecto importante para a compreensão da comunicação como constitutiva do humano, ressaltado por Fígaro é o fato dessa se efetivar pelas linguagens, especialmente a linguagem verbal, não como uma "ferramenta", que expressaria o pensamento do exterior para o interior, mas como um meio de "produção da vida em sociedade".

No texto "Enunciação e construção do sentido" (BRANDÃO, 2012), a autora discute questões da Análise do Discurso - AD na perspectiva de autores que são a referência básica no desenvolvimento acerca dos discursos analisados na tese, porque me situaram nos aspectos linguísticos e extralinguísticos do processo discursivo, nas suas aproximações e distanciamentos, como essa autora mesmo destaca. 
A perspectiva teórico-metodológica adotada foi justamente a de tratar a linguagem verbal, "no âmbito das relações de sentidos, construídas no processo comunicacional, na formulação de enunciados e discursos" (FÍGARO, Op. Cit, p.10), estando, contudo, atenta ao processo histórico que se apresentou na pesquisa. Os autores referenciados compareceram nas análises na medida em que foram suscitados, embora muitas vezes não houvesse menção a eles, juntamente com outros pesquisadores que estudam os modos de existência da população caatingueira, a exemplo da professora Maria Rita do Amaral Assy ${ }^{7}$ e do professor Esmeraldo Lopes ${ }^{8}$.

As pesquisas sobre o modo de existência dos caatingueiros demonstram que essa gente se faz, se constitui, na relação com o outro caatingueiro, sobretudo pela linguagem. É importante frisar isso porque não é um povo que cria monumentos arquitetônicos ou marcas visíveis, tal como a civilização ocidental reconhece, pelo contrário, as suas construções são perecíveis e a própria relação com a propriedade da terra nem sempre se constitui oficialmente por meio de títulos ou de outros documentos oficiais. Essa é uma comunicação essencial, uma vez que o seu corpo e tudo à sua volta, como o próprio chão onde vive e os corpos celestes que vislumbra são permeados de sentidos para a sua existência, que se manifesta essencialmente pela linguagem.

A oralidade, como forma agregadora das demais formas de expressão é a fonte dos enunciados produzidos cotidianamente para situar a si e aos outros, diante das adversidades. Todos sabem saber de tudo o que se passa ao seu redor e o modo como as pessoas lidam com as questões. Os enunciados do caatingueiro não visam uma explicação das coisas, mas a demonstração de como as coisas são: é assim. Essa expressão parte do saber da experiência e demonstra que essa gente está o tempo inteiro se situando e buscando nos situar nos processos em discussão. Há muito ainda a ser pensado sobre a linguagem dos povos tradicionais, considerando o modo como foram construindo a sua linguagem e se construindo nesse processo.

\footnotetext{
${ }^{7}$ Professora Dra, psicóloga, aposentada do Departamento de Ciências Humanas III, da Universidade do Estado da Bahia - UNEB, pesquisadora dos modos de existência da população catingueira.

${ }^{8}$ Professor Msc, sociólogo, aposentado, pesquisador dos modos de existência da população caatingueira
} 
A formação étnica dos caatingueiros envolve muitas origens e é possível que os conhecimentos sobre outros povos ajudem a mostrar a singularidade de sua comunicação. No mundo deles, as palavras podem vir antes das coisas, o que muda muito a relação com as palavras e com o próprio mundo. É o caso, por exemplo, das palavras não poderem ser ditas para não serem atraídas. Por exemplo, ao se dizer o nome de uma certa doença, diz-se: aquela doença; quando está se contando que algo feriu uma pessoa, diz-se: lá nela. Esse modo de se situar no mundo tem de certa forma, uma aproximação com o que Santana (2019) viu no seu estudo sobre a "Cosmologia africana dos bantu-kongo por Bunseki Fu-Kiau: tradução negra, reflexões e diálogos a partir do Brasil"”. Esse autor cita o pesquisador argentino Adolfo Colombres, quando esse afirma que a imagem vem depois da palavra. "No pensamento bantu, a imagem não é anterior à palavra, já que é o 'nommo' que engendra a imagem da coisa, tão logo tenha criado a coisa. Ao nomear o objeto ausente, a palavra transforma-o em imagem ou 'se' transforma em imagem" (SANTANA, 2019, p. 164-5).

O esforço aqui é justamente fazer ver os sentidos que são produzidos por essa forma de comunicação, tanto na sua materialidade linguística, quanto no seu contexto de enunciação e de produção discursiva. Essa materialidade está presente no que se diz, mas especialmente no como se diz. É um dizer fazendo, como as cercas no discurso de seo Domingos ao se referir às estratégias usadas pelos caatingueiros para impedir a passagem da empresa de energia eólica pelas suas terras. Esse discurso não explica, situa, leva a crer, a fazer, a ser.

\section{A comunicação se fazendo na comunicação: a voz do caatingueiro não estava prevista}

Para o desenvolvimento das análises das entrevistas e dos documentos elencados, busquei me situar teoricamente e metodologicamente nas relações entre texto, enunciado e discurso, na tentativa de compreender ativamente os processos comunicacionais dos caatingueiros, adotando uma postura de tradutora dos sentidos

\footnotetext{
9 Tese apresentada ao Programa de Pós-graduação em estudos da tradução do Departamento de Letras Modernas da Faculdade de Filosofia, Letras e Ciências Humanas da Universidade de São Paulo.
} 
produzidos no contexto dos conflitos vivenciados pelas transformações dos seus modos de vida. O texto produzido na forma de tese foi tecido ao longo do processo de pesquisa, o qual mostrou que não existia um discurso já consagrado. O momento da pesquisa coincide com o momento de elaboração do discurso em um processo comunicacional que estava acontecendo.

O texto é um tecido, confeccionado por uma inteligência; desse ponto de vista, tem um responsável, um autor: uma industriosa máquina humana de produção. Mas, o texto só aparece como um produto industrioso quando enunciado, torna-se discurso. Quando entra numa corrente histórica. Entra no rio de significados com outros discursos, fazendo sentido à medida que está em relação e em diálogo com outros". (FÍGARO, 2012 p.13).

O texto/tese é, portanto, esse tecido linguístico, que neste caso buscou imprimir o estilo, o modo de falar, de dizer do caatingueiro, privilegiando no discurso as palavras e as expressões usadas por eles. A autoria e a responsabilidade final são da pesquisadora, mas indubitavelmente, construído coletivamente. Essa construção partiu dos textos vivenciados no cotidiano de conflitos admitidos pelos caatingueiros, os quais foram se transformando em enunciados na medida em que passaram a comunicar as suas questões, as tensões, dúvidas e inquietações até então ignorados pelos responsáveis dos projetos modernizantes que adentram o seu mundo. Nesse sentido, a tese seja justamente os enunciados sobre os conflitos que não aparecem nas formas hegemônicas dos discursos.

A voz do caatingueiro não estava prevista. O direito à voz não estava instituído. Ela foi acolhida na tese. "O texto é potencialmente um enunciado e passa a ser enunciado quando cumpre a função comunicacional, produzido por um enunciador, sujeito histórico, situado, que entra na comunicação, ou seja, apresenta-se, revela-se na enunciação" (FÍGARO, 2012, p.13). Vale ressaltar que não é somente o sujeito, mas o contexto também constitui esse processo e pode-se dizer que a fala transcrita passou então à condição de enunciado ao longo da pesquisa. A própria tese pretendeu fazer parte do processo comunicacional sobre o qual ela se debruça.

\section{Comunicação como ato, criação: um modo de ver, agir, pensar, realidade}

Em Bakhtin/Voloshinov (2006, p. 127) encontramos, 
Compreender a enunciação de outrem significa orientar-se em relação a ela, encontrar o seu lugar adequado no contexto correspondente. A cada palavra da enunciação que estamos em processo de compreender, fazemos corresponder uma série de palavras nossas, formando uma réplica. Quanto mais numerosa e substanciais forem, mais profunda e real é a nossa compreensão. Assim, cada um dos elementos significativos isoláveis de uma enunciação e a enunciação toda são transferidos nas nossas mentes para um outro contexto, ativo e responsivo. A compreensão é uma forma de diálogo, ela está para a enunciação assim como uma réplica está para outra no diálogo. Compreender é opor à palavra do locutor uma contrapalavra.

Nesse processo de tradução/compreensão ativa busquei dialogar com os entrevistados, tanto no momento da entrevista, quanto diante da transcrição no momento da análise, tornando potente as suas vozes, os sentidos dos seus processos enunciativos, tão caros para esse povo. Assim, busquei me fazer presente, atenta e responsavelmente ativa diante da construção dos processos de enunciação e dos enunciados formulados pelos entrevistados, vendo e me fazendo ver no outro a partir das várias palavras ditas nos diálogos que se intercruzaram na tese.

O princípio arquitetônico supremo do mundo real do ato é a contraposição concreta, arquitetonicamente válida, entre eu e outro. A vida conhece dois centros de valores, diferentes por princípio, mas correlatos entre si: o eu e o outro, e em torno destes centros se distribuem e se dispõem todos os momentos concretos do existir. [...] Esta divisão arquitetônica do mundo em eu e em todos aqueles que para mim são outros não é passiva e casual, mas ativa e imperativa. Esta arquitetônica é tanto algo dado, como algo a-ser-realizado [danai zadana], porque é a arquitetônica de um evento (BAKHTIN, 2010, p. 142-3)

Considerando esse princípio arquitetônico descrito por Bakhtin, estabeleci uma ponte entre mim e os outros possíveis, nos valendo da Análise do Discurso (AD), assim como de outros campos do saber, como a filosofia, a linguística, a antropologia, a sociologia e a pedagogia, entre outros. De alguma forma esses saberes foram buscados para efetivar os propósitos aqui colocados. Considerei assim como Fígaro (2012, p.10) que "o campo da comunicação tem por objeto conhecer o processo comunicativo, ou seja, as interações que se dão entre sujeitos históricos e os modos de produção/recepção de técnicas, estéticas e sentidos dessas inter-relações”. Nessa perspectiva, os processos comunicativos nesta pesquisa se referem às interações entre os sujeitos, mas 
especialmente, ao modo como o caatingueiro desenvolve os seus processos de enunciação, considerando os seus modos de pensar, de se fazer caatingueiro, transformando a si e interferindo de forma coletiva, no contexto das transformações que ora atravessam o seu mundo.

Esse processo de enunciação foi atentamente visto, ouvido, percebido por mim na sua materialidade, ou seja, no texto, no enunciado e no discurso. Nessa escuta e escritura, salta uma Língua Caatingueira, um pouco diferente daquela língua portuguesa tal qual habitualmente costumamos ouvir, parece não existir aí uma gramática inteiramente prevista. Na fala há a performance da voz. Assim, não dá para resumir a fala do caatingueiro porque não são as palavras somente que definem o texto, mas as relações, os desenhos que a gramática faz, desenho do diálogo.

Nessa perspectiva, os enunciados não são apenas representações, ou seja, não re apresentam mentalmente o que está no mundo, através da mente: língua; e mundo: coisas, fatos. Mas agem como ato/ação, criam um modo de ver, agir, pensar, estar no mundo, tem ação material, realidade. Quando o enunciado é um fato, ele tem uma existência própria no tempo e no espaço. Quando ele é um ato, a ação dele pode perdurar, não está demarcado no tempo e no espaço. A conversação não se dá por inteiro, é virulenta.

Um exemplo desse tipo de enunciado como ato/criação aconteceu durante a pesquisa, quando a caatinga pegou fogo em uma área do Parque Boqueirão da Onça, em Sento-Sé ${ }^{10}$. O comentário das pessoas era: aí tem coisa. Primeiro, porque não havia uma explicação plausível, a caatinga nessa região não costuma pegar fogo e segundo, porque são muitos os interesses em jogo, atualmente. É um outro tipo de atenção, pistas vão surgindo, há uma construção coletiva do discurso. Ele é assim, elaborado coletivamente, cada um acrescenta com a sua experiência ou vivência. Essas conversações são uma prática diária nos terreiros das casas, nas aguadas, embaixo dos imbuzeiros e nas pequenas praças das sedes dos povoados. No caso deste processo de pesquisa, o discurso do caatingueiro não estava previamente formulado, foi se fazendo no processo e o próprio processo de pesquisa se desenvolveu nas conversações, na enunciação dos problemas apresentados, ouvidos aqui e ali.

\footnotetext{
${ }^{10}$ Esse episódio ocorreu no mês de setembro de 2018. Portanto, já com esta pesquisa em andamento.
} 
De acordo com Brandão (2012, p. 19), “o discurso ultrapassa o nível puramente gramatical, linguístico. O nível discursivo apoia-se sobre a gramática da língua e sobre os aspectos extralinguísticos que condicionam a sua produção”. Essa compreensão considera o fato de que o discurso diz respeito também às condições empíricas de sua produção e elas nos interessam, sobretudo porque se vincula ao funcionamento da língua como uso. Nessa pesquisa, é preciso lembrar, a língua está em movimento, na formulação de enunciados e processos de enunciação que provavelmente se desenvolveram no ato da pesquisa, uma vez que as coisas estavam ocorrendo e nunca antes tinham ocorrido. Um exemplo dessa situação é a relação entre as pessoas e as onças. Os caatingueiros não sabiam que elas estavam previstas no Parque e que eles próprios, não. Foi aos poucos e ao longo do processo de pesquisa que a coisa foi se clarificando, até chegar a dizer: a onça tem voz. Esse animal que sempre disputou o território com os criadores, agora reinará, absoluto. Esse é um discurso que emerge das conversações. Foi preciso então, esperar o tempo em que a informação chegaria aos moradores do lugar. Todos esses processos enunciativos se deram a partir dos conhecimentos linguísticos disponíveis e dos conhecimentos extralinguísticos construídos no contexto histórico necessários para dar conta das questões propostas na pesquisa.

\section{Comunicação do caatingueiro: algo mais filosófico, experiência, reflexão da vivência}

Para o caatingueiro, a experiência é algo mais filosófico, é praxis; é a extração de uma sabedoria, uma reflexão da vivência. Ao falar sobre o saber da experiência, Bondía (2002, p.21) ressalta que:

A experiência é o que nos passa, o que nos acontece, o que nos toca. Não o que se passa, não o que acontece, ou o que toca. A cada dia se passam muitas coisas, porém, ao mesmo tempo, quase nada nos acontece [...] A primeira coisa que gostaria de dizer sobre a experiência é que é necessário separá-la da informação. E o que gostaria de dizer sobre o saber de experiência é que é necessário separá-lo de saber coisas, tal como se sabe quando se tem informação sobre as coisas, quando se está informado [...] A experiência funda também uma ordem epistemológica e uma ordem ética. $\mathrm{O}$ sujeito passional tem também sua própria força, e essa força se expressa produtivamente em forma de saber e em forma de práxis. O que 
ocorre é que se trata de um saber distinto do saber científico e do saber da informação, e de uma práxis distinta daquela da técnica e do trabalho.

Esse saber da experiência "que nos passa", "que nos acontece", "que nos toca", se faz e se refaz no contexto de práticas discursivas em que os sujeitos, neste caso, os caatingueiros, organizam, planejam, inventam e se reinventam coletivamente, cotidianamente. Para a AD, de acordo com Brandão (2012, p. 26)

[...] esse sujeito essencialmente marcado pela historicidade, não é o sujeito abstrato da gramática, mas um sujeito situado no contexto sócio-histórico de uma comunidade, num tempo e espaço concretos. É um sujeito interpelado pela ideologia, sua fala reflete os valores, as crenças de um grupo social. Não é único, mas, divide o espaço de seu discurso com o outro, na medida em que, na atividade enunciativa, orienta, planeja, ajusta sua fala tendo em vista um interlocutor real, e também porque dialoga com a fala de outros sujeitos, de outros momentos históricos, em um nível interdiscursivo.

O sujeito do discurso da $\mathrm{AD}$ já ganha uma perspectiva histórica, quando “[...] se constitui, se reconhece como tendo uma determinada identidade na medida em que interage com outros discursos, com eles dialogando, comparando pontos de vista, divergindo, etc". (BRANDÃO 2012, p. 26). Nesse sentido, o caatingueiro se reconhece como catingueiro no caatingueiro. Por outro lado, os estudos sobre as populações caatingueiras realizados por Lopes (2012) e Assy (2014), assim como a pesquisa ora apresentada demostram que na experiência discursiva, o caatingueiro não confronta com o seu interlocutor, ao que ele diz, acrescenta algo. No entanto, isso não impede que haja tensão entre ambos. Esse aspecto da linguagem pesquisada se relaciona com o conceito de formação discursiva da $\mathrm{AD}$ ao pressupor que toda formação discursiva é atravessada por outras formações discursivas. "[...] uma formação discursiva está sempre em interação com outras formações discursivas em que vários discursos estão ora em relação de conflito, ora de aliança, e a linguagem é vista como uma arena de lutas.” (p. 22)

A formação sócio-histórica do caatingueiro se dá no contexto de mudanças de configurações políticas, econômicas e geracionais, sem contudo, haver mudanças no ambiente, especialmente no seu habitat, considerando que o bioma caatinga permanece bastante preservado e o modo de vida tradicional, também permanece quase inalterado, 
não havendo assim atualização histórica ${ }^{11}$. Nesse sentido, o discurso é histórico, porque o sujeito é histórico. O caatingueiro experimenta a história de uma forma cíclica. As transformações são contingencias de uma mesma existência. Possivelmente, eles já estejam onde gostariam de estar. Para esse povo o mundo não é uma ideia, mas uma experiência, não está previamente estabelecido; nada é totalmente garantido. Algumas expressões demonstram essa percepção do mundo. Ex: se chover...; se Deus quiser...

Nesse sentido, as reflexões de Bakhtin/Voloshinov (2006, p. 122) sobre enunciação e interação social são mais esclarecedoras acerca das questões observadas na pesquisa. "A estrutura da enunciação é uma estrutura puramente social. A enunciação como tal só se torna efetiva entre falantes". Esses falantes, os caatingueiros, têm consciência do seu mundo, do papel e do poder da palavra na constituição do humano, na interação com outros.

\section{A narrativa pode criar existência, experimentando as palavras até poder dizer}

Trazendo o poder da palavra para a filosofia da linguagem de Bakhtin, temos que a palavra é plurivalente, por isso, o dialogismo é uma condição constitutiva do sentido. A partir dessa compreensão esse filósofo,

[...] elabora o conceito de polifonia, analisando textos literários e da literatura popular, por ele denominada também de carnavalesca, em que o narrador se investe de uma série de máscaras e representa várias vozes a falarem simultaneamente, sem que uma dentre elas seja preponderante e julgue as outras. (BRANDÃO, 2012, p. 33)

Nessa perspectiva, o pensamento de Authier-Revuz (2004) nos ajuda a pensar essa questão, uma vez que radicaliza o princípio do dialogismo, explorando-o sob a forma de heterogeneidade. Essa autora, "[...] elabora uma teoria da enunciação em que o princípio do dialogismo resulta numa concepção do discurso assentada na característica heterogênea da linguagem e numa concepção de sujeito afetado pela divisão entre o consciente e o inconsciente" (BRANDÃO, 2012 p. 35). Esse pensamento é assentado na compreensão de que o discurso é heterogêneo porque o sujeito é heterogêneo, afetado pelo outro-interlocutor, pelo outro-interdiscursivo.

\footnotetext{
${ }^{11}$ A esse respeito ver Lopes (2012)
} 
Essa diversidade de textos que compõem os discursos dos caatingueiros foi afetada pelos discursos que circulam no cotidiano das conversas e se manifestaram na pesquisa como verbalização/ação, quando por exemplo, as cercas saltam aos nossos olhos no dizer fazendo do seo Domingos; quando a professora Francisca interfere na fala do seo Chicada, seu esposo, mostrando o que acontece quando os funcionários da Brennand tentam cortar os imbuzeiros; quando o professor Domingos e seo Domingos questionam o $1 \%$ pago pela empresa pela produção de cada torre eólica, uma vez que o conceito de propriedade para o caatingueiro está ligado à sua existência e para o empresário está ligado ao capital privado. Essa diversidade de discursos entrecruzou a minha produção discursiva e levantou os problemas enfrentados e que puderam ser ouvidos ao longo desta pesquisa.

Essa propriedade da linguagem que pode ser “[...] apreendida no fio do discurso, na superfície, na materialidade linguística do enunciado, através de marcas, indícios que mostram/sinalizam o 'outro'," (BRANDÃO 2012 p. 35) foi fortemente perseguida por mim, através de uma escuta e de uma escritura atenta para evidenciar o que se apresenta na linha e não somente nas entrelinhas das falas transcritas. São delimitações mostradas na superfície linguística, na materialidade linguística do enunciado, índices que denunciam o lugar de um e do outro, neste caso o lugar do caatingueiro, dos empresários, dos ambientalistas e o meu próprio lugar como pesquisadora.

Nesse contexto de produção de sentidos dos discursos produzidos, é preciso destacar mais uma vez, que os caatingueiros veem as coisas, assim como o discurso, acontecendo e nesse processo o sujeito vai se fazendo. A negociação para eles é precisa; a escolha da palavra é precisa. Existem marcas em seu discurso que não possuem sinônimos. Diante de uma situação em que a família possa ser julgada, por exemplo, sente uma contrariação, uma contrariedade que segue cortando, fulminando, dilacerando o coração. Esse processo de enunciação é um fenômeno que se produz e é histórico, abarca um período. Vemos o que emerge, o que salta.

Para o caatingueiro, a narrativa pode criar existência, experimentando as palavras até poder dizer. A significação está na frase e o sentido é do nível do enunciado. Assim, a nossa atenção foi centrada nem tanto nas informações, mas nos sentidos materializados nos fios discursivos enunciados, no como, na ação de 
enunciação. Essa foi a perspectiva adotada: uma audição atenta das falas, das suas palavras, com o intuito de fazer ver os sentidos que são produzidos, tanto na sua materialidade linguística, quanto no seu contexto de enunciação e de produção discursiva, buscando tornar sensíveis as expressões linguageiras realizando enfim, a sua comunicação.

\section{Considerações Finais}

O desenvolvimento do problema da tese se deu em meio ao desenvolvimento dos processos de enunciação e dos enunciados formulados pelos pesquisados. De início, já se sabia que havia uma grande tensão entre o modo de vida dessa população e os projetos de modernização que atravessam esse mundo.

As entrevistas transformaram-se em conversas, nas quais 'saltavam' uma língua portuguesa, fincada na vivência e na experiência de um fazer coletivo. Por essa razão, optei por não categorizar as falas dos entrevistados, dar explicações sobre o que era dito ou tão pouco extrair apenas as informações que porventura fossem consideradas relevantes. Exercitei as transformações que aqueles enunciados provocavam em mim, modificando a minha lógica de pensar ou me reconhecendo nela. Ao me aproximar do território existencial do caatingueiro, pude 'ver' os conflitos sendo situados nas suas falas. Havia um esforço para mostrar em palavras o que se via. Nesse momento, o problema de pesquisa foi sendo redimensionado: eles não eram ouvidos. As suas vozes não foram previstas em nenhum dos projetos em curso: instalação de Parques Eólicos e empresas mineradoras; criação do Parque de Conservação. O meu desafio então fora: como tornar sensíveis as expressões linguageiras do caatingueiro e como viabilizar na matéria escrita dessa tese esses processos comunicacionais de tal forma que se efetivasse uma comunicação? Não bastava ouvir as vozes dos caatingueiros, transcrevêlas e buscar meramente realizar uma transmissão, pois foi se configurando outra perspectiva de tratar aquilo que ocorria, mais do que a formulação de uma outra opinião a respeito. $\mathrm{O}$ ponto de vista caatingueiro não se limitava a interpor uma oposição, um confronto, nem mesmo uma resistência às mudanças que se faziam. Havia um pensamento vivo sobre o que se passava, produzido a partir do modo como experimentava-se tudo aquilo. 
Foi preciso, assim, redimensionar também o meu lugar de pesquisadora, me tornar uma tradutora das suas falas, contextualizando-as dentro do seu universo existencial e dos sentidos produzidos por elas. Nessa perspectiva, essas vozes tornaramse enunciados dos conflitos à medida que seus processos de enunciação puderam ser ouvidos, vistos e considerados. Entraram na corrente de comunicação estabelecida pela tese. Ela própria foi fazendo parte do processo comunicacional que se desenvolvia. Não é justamente isso que acontece quando pesquisamos? Acabamos fazendo parte da própria comunicação que se comunica. Vale a pena ressaltar que não havia uma perspectiva desde sempre concebida. Ao ser desenvolvida, abriu-se mais um campo de enunciação. Fui entendendo o que se passava, quais eram os problemas que eram enunciados na perspectiva dos caatingueiros, como também os caatingueiros serviam-se do momento da entrevista para erguer as palavras, achar jeito de dizer, tentando deixar muito claro o que estava sendo dito: 'entendeu?'.

Buscando tornar sensíveis essas expressões, coloquei-me como ouvinte e tradutora atenta das suas palavras, dos seus processos de enunciação e das formulações de seus enunciados. Nesse sentido, alguns autores da Análise do Discurso contribuíram para que eu pudesse dizer o que ouvia na língua 'das caatinga' e fazer ver essa comunicação na posição de "analista" dessa linguagem, no contexto dos sentidos produzidos por ela, especialmente porque é pela linguagem, sobretudo a oral, que essa gente se constitui como um povo. Ao ser desenvolvida, essa pesquisa pretendeu mostrar a perspectiva do caatingueiro, no modo como estão percebendo e enfrentando as transformações que estão ocorrendo em seu território, através dos seus processos comunicacionais.

\section{Referências}

ASSY, Maria Rita do Amaral. A força inventiva da voz ignorada. Tese (Doutorado em Psicologia Clínica). Pontifícia Universidade Católica de São Paulo - PUC - SP, 2014.

ASSY, Maria Rita do Amaral. A criação ignorada da existência. Universidade do Estado da Bahia - Juazeiro, 2017.

AUTHIER-REVUZ, J. Entre a transparência e a opacidade: um estudo enunciativo do sentido. Porto Alegre: EDIPUCRS, 2004. 
BAKHTIN, Mikhail (VOLOSHINOV). Marxismo e filosofia da linguagem. 16 ed. São Paulo, Hucitec, 2006.

BAKHTIN, Mikhail. Para uma filosofia do ato responsável. São Carlos: Pedro \& João Editores, 2010.

BRANDÃO, Helena Nagamine. Enunciação e construção do sentido. In: Comunicação e análise do discurso. São Paulo: Contexto, 2012.

BONDÍA, Jorge Larrosa. Notas sobre experiência e o saber de experiência. Revista Brasileira de Educação, 2002.

FÍGARO, Roseli (org). Comunicação e análise do discurso. São Paulo: Contexto, 2012.

GEERTZ, Clifford. A interpretação das culturas. 1 ed. Rio de Janeiro: LCT, 2008. KRENAK, Ailton. Ideias para adiar o fim do mundo. Companhia das Letras, 2019.

LAKATOS, Eva Maria; MARCONI, Marina de Andrade. Metodologia científica. $4^{\text {a }}$ Ed. - São Paulo: Atlas, 2004.

LOPES, Esmeraldo. Caatingueiros e Caatinga - A agonia de uma cultura. Maceió: Gráfica Grafipel, 2012.

SANTOS, Tiganá Santana Neves. A cosmologia africana dos bantu-kongo por Bunsenki Fu-kiau: tradução negra, reflexões e diálogos a partir do Brasil. Tese (doutorado) - Faculdade de Filosofia, Letras e Ciências Humanas da Universidade de São Paulo. São Paulo, 2019.

WOLTON, Dominique. Pensar a Comunicação. Brasília: Editor Universidade de Brasília, 2004. 